\title{
PITCH PROFILE OF THE GLOTTAL WHISTLE (M4)
}

\section{Michael Edward Edgerton, Samuel Tan, Gabriel Evans, Myung Hwa Jang, Bo Kyung Kim, Fung-Ying Loo, Kok-Chang Pan, Mohd Nasir Hashim}

\author{
Department of Fine Arts, Cultural Centre, Old Chancellory Building, 2nd Floor, 50603 Kuala Lumpur \\ Malaysia
}

\begin{abstract}
This paper presents a previously unreported method of laryngeal vocal sound production that is capable of producing pitches even higher than the whistle register (M3). Colloquially known as the glottal whistle (here referred to as M4), this method has a wider range than M3 and features frequent instances of biphonation, which is of interest for those involved with contemporary and improvised music. Pitch profile analyses of M4 have found the majority of fundamental frequency (f0) activity to be between 1 and $3 \mathrm{kHz}$, while the most frequently seen range was between 1000 to 1,500 Hz. Remarkably, multiple singers were able to produce fo higher than the highest tone on the piano.
\end{abstract}

(Keywords: glottal whistle, whistle register, M3, voice science, high fundamental frequency)

\section{INTRODUCTION}

The singing voice is a remarkable instrument that is capable of presenting enormous emotional depth and expressiveness in a wide variety of contexts. Whether utilizing technical virtuosity or the modesty of a single tone the voice has significant potential to realize diverse classes of sound output.

Extremes of vocal tessitura are numerous that extend from the very low to the very high. In this paper we will focus on a previously unreported method of high pitch singing. Before that, it is worth noting that for the female voice, some methods of high pitched singing include the soprano coloratura which features a fundamental frequency (f0) range from approximately B3 $(247 \mathrm{~Hz})$ to A6 $(1760 \mathrm{~Hz})$ [1-2]. While, in the upper region of the coloratura range, a phenomenon known as the whistle register (M3) is often used. M3 has in recent years gained more attention by performers of classical, jazz, popular and contemporary music, which has begun to receive increased scientific investigation [3-8]. Sitting higher than the two main laryngeal mechanisms (M1, chest register \& M2, head register) M3 typically has a pitch range of approximately 1000 to $2000 \mathrm{~Hz}$, though in exceptional cases it may go much higher [710].

An unusual instance of high voice production was first reported in 1902 that described some sort of laryngeal whistle (Spalttöne) that was subsequently referred to in English as a "Chink
Tone". This phenomenon ranged from approximately $775 \mathrm{~Hz}$ (G5) to $2760 \mathrm{~Hz}$ (F7) [8, 11-12], though it is unclear to what exactly the author was referring to in his paper.

High pitched male singing includes the classical tenor voice which ranges from approximately A\#2 $(116 \mathrm{~Hz})$ to F5 $(698 \mathrm{~Hz})$ [13], while the male falsetto ranges from approximately A3 (220 $\mathrm{Hz})$ to $\mathrm{G} 5(784 \mathrm{~Hz})$ [14]. The yodel which occurs in a variety of western and nonwestern (ethnic, folk and popular) music often features registral oscillation from modal to falsetto mostly at an octave in the male voice [15]. Utilizing a naturally high male soprano or falsetto, the countertenor voice encompasses a range from approximately G3 $(196 \mathrm{~Hz})$ to G5 $(784 \mathrm{~Hz})$ [16]. A different type of high pitched male singing features not only the range but also the quality of the female voice. Males with this disorder, known as the Kallmann Syndrome that occur as the result of a genetic disorder characterized by a failure to complete puberty or a decreased function of the glands that produce sex hormones (hypogonadism), have a voice quality similar to that of women. The condition has a low prevalence, and is estimated at 1:10,000 males. The best-known singer with the Kallmann syndrome is the jazz vocalist Jimmy Scott who has a range of approximately C3 to F5 [17-21]. In a completely different way, the Castrato was a high male voice whose physiology was, by today's standards, cruelly and artificially altered to produce a voice quality and range aligned with the soprano [22]. In 1904 the last castrato Alessandro Moreschi was 
recorded in the Sistine Chapel in the Vatican [23]. In his recording of "Hostias Et Preces" by Eugenio Terziani (1824-1889) [24], the pitch profile reveals the highest pitch at $800 \mathrm{~Hz}(\mathrm{G \# 5})$. It was reported that the legendary Farinelli had a voice spanning over three octaves, from C3 (131 Hz) to D6 (1175 Hz) [25] (Table 1).

Table 1. Listing of high pitched oscillatory behaviors with approximate ranges

\begin{tabular}{|c|c|c|}
\hline \multicolumn{3}{|c|}{$\begin{array}{l}\text { Pitch range profile of high oscillatory voiced } \\
\text { behaviors }\end{array}$} \\
\hline $\begin{array}{l}\text { Soprano } \\
\text { coloratura }\end{array}$ & $\mathrm{B} 3$ to $\mathrm{A} 6$ & $247 \mathrm{~Hz}$ to $1760 \mathrm{~Hz}$ \\
\hline $\begin{array}{l}\text { Whistle } \\
\text { register (M3) }\end{array}$ & B5 to $\mathrm{C} 7$ & $\begin{array}{l}1000 \mathrm{~Hz} \text { to } 2000 \\
\mathrm{~Hz}\end{array}$ \\
\hline $\begin{array}{l}\text { Spalttöne } \\
\text { (“Chink") }\end{array}$ & G5 to F7 & $\begin{array}{llll}775 & \mathrm{~Hz} & \text { To } & 2760 \\
\mathrm{~Hz} & & & \end{array}$ \\
\hline Tenor voice & $\begin{array}{l}\text { A\#2 to } \\
\text { F5 }\end{array}$ & $116 \mathrm{~Hz}$ to $698 \mathrm{~Hz}$ \\
\hline Male falsetto & A3 to G5 & $220 \mathrm{~Hz}$ to $784 \mathrm{~Hz}$ \\
\hline Yodel & $\begin{array}{l}\text { Chest to } \\
\text { mid, mid } \\
\text { to head }\end{array}$ & Varies \\
\hline Countertenor & G3 to G5 & $196 \mathrm{~Hz}$ to $784 \mathrm{~Hz}$ \\
\hline $\begin{array}{l}\text { Kallmann } \\
\text { Syndrome }\end{array}$ & $\mathrm{C} 3$ to $\mathrm{F} 5$ & $130 \mathrm{~Hz}$ to $700 \mathrm{~Hz}$ \\
\hline Castrati & C3 to D6 & $131 \mathrm{~Hz}$ to $1175 \mathrm{~Hz}$ \\
\hline
\end{tabular}

However, there is another form of laryngeally produced voice that sits in an even higher range which is known as the glottal whistle (in this study referred to as M4) [26]. This type of production is seen in contemporary and freeimprovised music with instances reported in nonartistic domains, such as during children's play, childbirth and perhaps in animal vocalization, but in human singing has received no reported scientific investigation [27].

While singing in M4 it may not be possible to control pitch with any precision, nor in many cases whether it is monophonic or multiphonic. Therefore it is relevant to consider whether M4 is best considered a register or some other category of unusual vocal behavior. However, like the often reported vocal registers M1, M2 and $\mathrm{M} 3$ it is possible to transition into and out of M4 from chest, mid or head registers. For normal oscillatory singing these regions of transition have been identified as follows: the primo passaggio from $\mathrm{M} 1$ to $\mathrm{M} 2$ has been reported to occur around E4-F4 ( 340 Hz) [7, 10, 14, 28]. A second transitional area, the secondo passaggio occurs in the region of C5 to G5 ( $500-700$ $\mathrm{Hz}$ ), which some have suggested more appropriately divides the female head register into middle and upper tessitura [14, 28-30]. A third, larger region has been reported higher in the soprano voice, corresponding approximately to E5 - G6. When a soprano is able to sing in the whistle register, a transition between M2 and M3 will likely occur above E5 [3-5, 8, 10, 31-35].

\section{METHODS}

This study analysed 41 voice samples from eight singers producing M4 and two excerpts from two singers producing M3. We chose the samples based upon perceptual evaluation suggesting episodes featuring clear instances of M4 (or M3 in two cases). These excerpts were digitally extracted from publicly available CD recordings and private \& rehearsal recordings by author MEE.

All samples used recordings from solo singers that were mostly unaccompanied (the exception being the recording of Erna Sack from 1936 Una voce poco fa from il barbiere di Siviglia) [36, 37]. For M3 the singers on the recorded samples included Erna Sack (the German Nightingale) an opera singer, and Adam Lopez a pop musician from Australia. For M4, the singers all had a career or interest in contemporary classical music and/or jazz to free improvisation. These singers included: Jaap Blonk, Anna Homler, Almut Kuehne, Juergen Neubauer, Amy Stebbins, Demetrio Stratos, Rebekka Uhlig and Angela Rademacher née Wingerath [38-46].

The recordings utilized no processing of any kind, neither dynamically (dynamic compression or enhancement) nor spectrally (filtering, pitch shifting, chorusing, phasing). The samples were recorded at a sampling rate of $44100 \mathrm{~Hz}$ with a resolution of 16 bits/sample. The window length was set to $30 \mathrm{~ms}$ ( 0.03 seconds) which produced a narrow band spectrogram with a bandwidth of $43 \mathrm{~Hz}$. Each frame used the part of the sound that lay between 0.015 seconds before and after the centre of that frame.

\section{RESULTS}

\section{Pitch and range}

M4 exists in a high range. In comparison, the fundamental frequency (f0) of the whistle register (M3) typically ranges from 
approximately B5 $(990 \mathrm{~Hz})$ to A6 $(1760 \mathrm{~Hz})[7-$ 10]. Figure 1 shows an example of the German nightingale (Die Deutsche Nachtigall) Erna Sack from a recording in 1936 while singing "Una voce poco fa" from Il barbiere di Siviglia by Gioacchino Rossini who switches from head to whistle register. However, sometimes the fo of M3 may go much higher. Figure 2 shows a

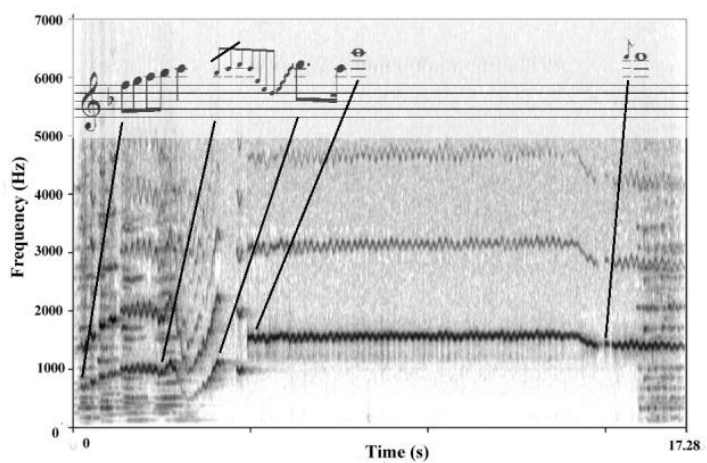

Figure 1. Erna Sack (1936); "Una voce poco fa" from Il barbiere di Siviglia, 1816 by Gioacchino Rossini with a lengthy sustained tone on G6 in M3 register - this excerpt features both the head (M2) and whistle registers (M3) (Rossini, 1936).

M4 typically has a range from approximately 1000 to $2500 \mathrm{~Hz}$, though the f0 may go much higher. Figure 3 shows an excerpt of singing in M4 with a pitch range from approximately 1 to $2.5 \mathrm{kHz}$ that was sung by Anna Homler [39] in her improvisation titled Signals. In 1978 Demetrio Stratos released an album titled Cantare la voce [43] which featured an improvisation titled Passaggi.

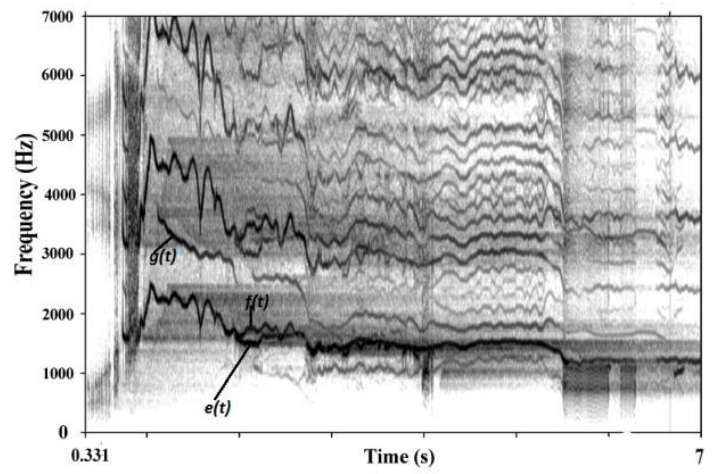

Figure 3. Glottal whistle (M4) by Anna Homler in "Signals" featuring biphonic and monophonic instances. The f0 ranges approximately between 1 and $2.5 \mathrm{kHz}$ (Homler, 1989). spectrogram made from a televised broadcast recording from 2005 at the Channel 7 studios in Australia, in which the pop singer Adam Lopez [47], who had already publicly sung a D7, extended the highest sung note (oscillatory mode) to a C\#8 (4435 Hz) and thus setting a new Guinness World Record.

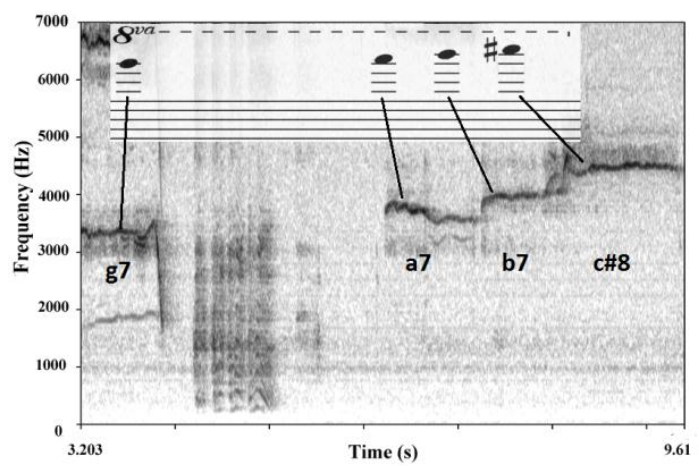

Figure 2. Adam Lopez producing the tone $\mathrm{C} \# 8$ $(4565 \mathrm{~Hz})$ at the end of a 4 note sequence (G7 - A7B7-C\#8) (Lopez, 2005).

Figure 4 shows a spectrogram of an excerpt from this performance in which Stratos produced a very high glottal whistle whose peak at 6503 $\mathrm{Hz}$ was nearly $2000 \mathrm{~Hz}$ above the highest point

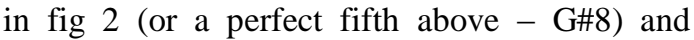
constitutes the highest laryngeally produced fundamental frequency reported.

M4 features an unusual timbral quality that resembles a whistle produced deep in the throat. Significantly, M4 features harmonic content that ranges from full, rich tones to those closer to a sine wave. For an example of richer, fuller tones note how figure 3 features many harmonics as well as combination tones that contribute to the relativeness richness of timbre.

The lowest pitches for the majority of M4 samples were near $1 \mathrm{kHz}$ while the highest pitches were generally lower than $4 \mathrm{kHz}$. Figure 5 shows an instance of singing in M4 below 1 $\mathrm{kHz}$, at the marked instance the f0 is approximately $750 \mathrm{~Hz}$ (F\#5). 


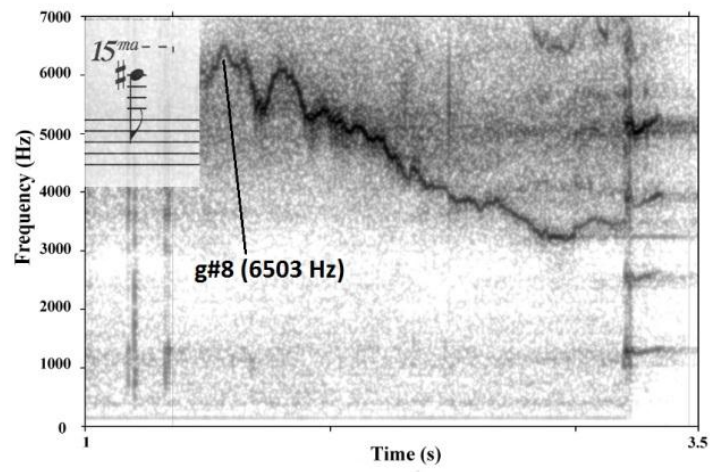

Figure 3. Passagi by Demetrio Stratos producing a very high glottal whistle (M4) - at the cursor the whistle follows a preparatory phase with its highest peak at $6503 \mathrm{~Hz}$, approximately a G\#8, or a P5 above the peak in fig. 2! (Stratos, 1978).

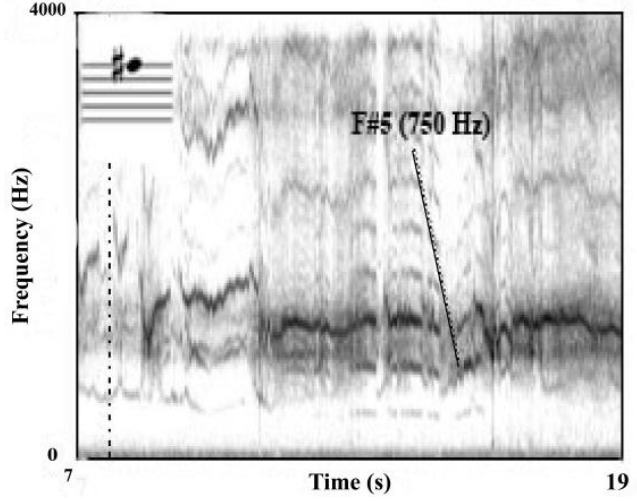

Figure 4. Anaphora by Michael Edward Edgerton and sung by Rebekka Uhlig who produces a very low M4 tone. Generally M4 pitches are above 1 $\mathrm{kHz}$, however in this sequence the $\mathrm{f} 0$ is near 750 $\mathrm{Hz}$ (F\#5).

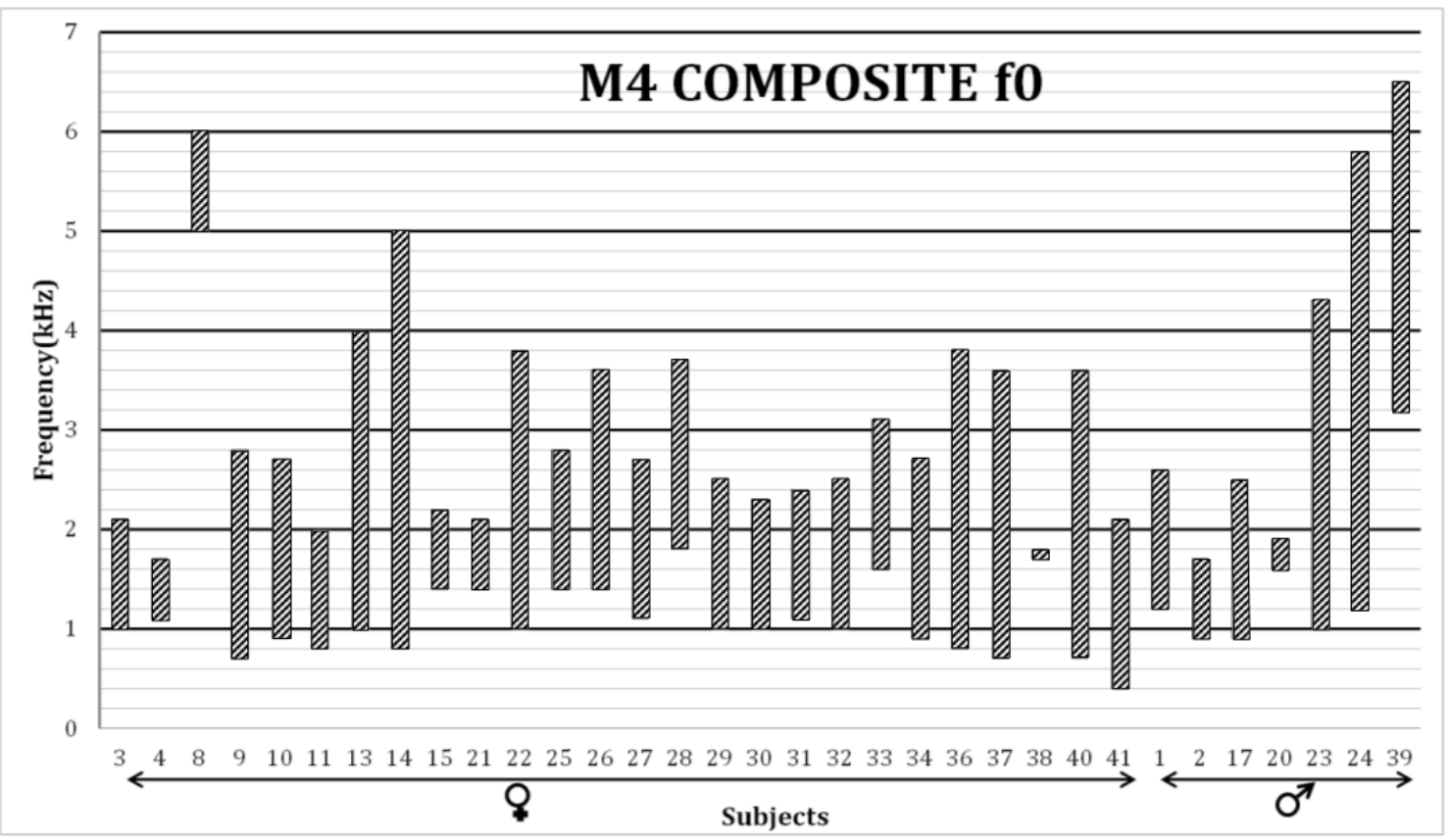

Figure 5. Pitch (fundamental frequency) range profile for 33 samples

Figure 6 shows the composite ranges for 35 different M4 samples. In this pitch profile the majority of activity lay between 1 and $3 \mathrm{kHz}$. The gender distribution of these samples consisted of 26 women, 7 men. Surprisingly the highest f0 was produced by a male while the lowest f0 was produced by a female. No claim is made here favouring one gender over the other regarding proficiency, ability, likelihood, nor ease of M4 production.

Remarkably, the widest M4 range featured an extent of $4.6 \mathrm{kHz}$, while the narrowest range consisted of a nearly stable tone with a $100 \mathrm{~Hz}$ deviation over time. Figure 7 shows that the M4 range that occurred most often was 1.1 to 1.5 $\mathrm{kHz}$ at $28 \%$ of the time, while the ranges .6 to 1 $\mathrm{kHz}$ and 2.6 to $3 \mathrm{kHz}$ each occurred $17 \%$ of the time. Next, figure 8 reveals that exactly one-half of the samples featured a lower threshold at 1 $\mathrm{kHz}(+/-200 \mathrm{~Hz})$, while another $33 \%$ were at 1.5 $\mathrm{kHz}$. Interestingly, the upper threshold for M4 featured a more uniform distribution, occurring at $2.5 \mathrm{kHz}-25 \%, 2 \mathrm{kHz}-19 \%, 3.5 \mathrm{kHz}-14 \%$. 


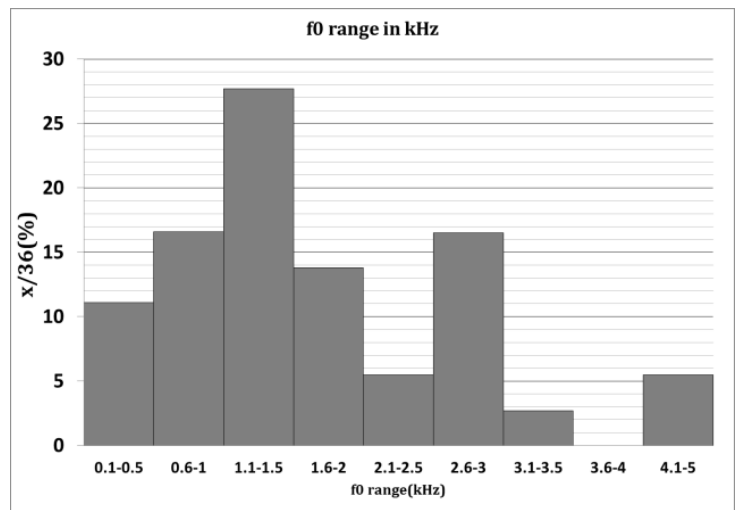

Figure 6. A pitch range of $1-1.5 \mathrm{kHz}$ was seen most often in M4

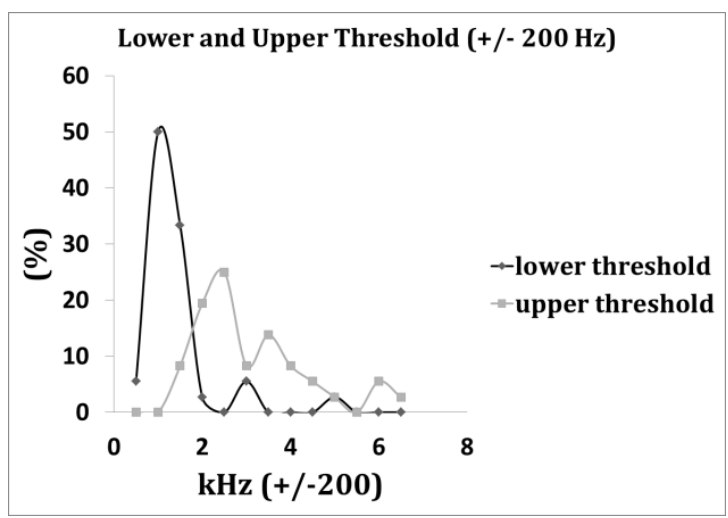

Figure 7. 50\% of M4 featured low pitches at $1 \mathrm{kHz}$ while upper pitches occurred most often at $2.5 \mathrm{kHz}$

Table 2. composite ranges itemized by gender, with musical notation and its placement on keyboard

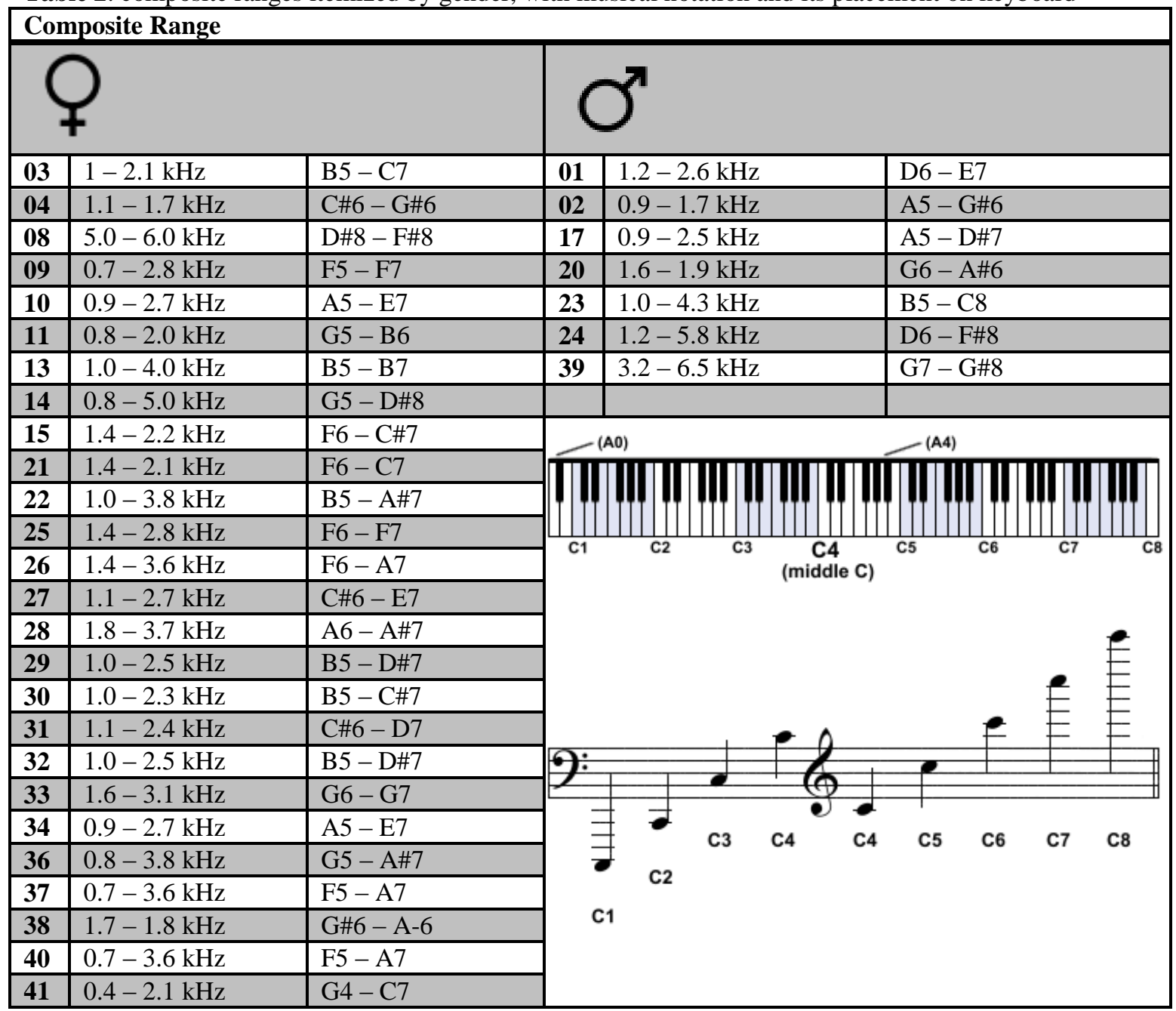

Table 2 offers another view of the composite ranges for each singer, itemized according to gender that additionally pairs musical notation with its visual placement on the piano keyboard.
It may be worth noting that samples \# $08,14,24$, and 39 feature upper pitch thresholds higher than the highest note on the piano. 


\section{DISCUSSION}

Singing at high pitches has for a very long time occupied a unique role in classical, popular, world and experimental performance $[26,36,48$, 49]. In the literature $M 3$ is considered to occupy the highest known register of laryngeally produced sound $[7,10]$. However, this paper provides evidence that there is one method utilizing laryngeally produced sound that features an even higher tessitura, known here as M4.

The practical experience of author MEE as composer, pedagogue and performer often involved with M4 production has revealed that it may not be possible to control exact pitch with any precision. Therefore, although this form of sound production is produced laryngeally, we must question whether it is best considered as a register. Two arguments for considering M4 as register are: 1) the numerous instances of transitions into and out of M4 from M1/M2/M3/asymmetry, and; 2) the ability to combine M4 with another mode, which is already known in the case of [imitated Tibetan] Chant which for some subjects combines M1 with M0 (here meaning vocal fry) $[26,27,50]$.

\section{REFERENCES}

1. Coffin, B. (1960). Coloratura, Lyric and Dramatic Soprano, Vol. 1. Rowman \& Littlefield Publishers: Lanham, Md.

2. Kob M., Henrich N., Herzel H., Howard D., Tokuda I. and Wolfe J. (2011). Analysing and understanding the singing voice: recent progress and open questions. Current Bioinformatics 6: 362-374.

3. Walker J.S. (1988). An investigation of whistle register in the female voice. $J$. Voice 2: 140-50.

4. Miller D.G., Schutte H.K. (1993). Physical definition of the flageolet register. J. Voice 7(3): 206-12.

5. Herzel H., Reuter R. (1997). Whistle register and biphonation in a child's voice. Folia Phoniatr. Logop. 49: 21624.
6. Švec J. G. (2000). On vibration properties of human vocal folds: Voice registers, bifurcations, resonance characteristics, development and application of videokymography. doctoral dissertation, Groningen: University of Groningen.

7. Henrich N. (2006). Mirroring the voice from Garcia to the present day: Some insights into singing voice registers. Logoped. Phoniatr. Vocol. 31(1): 3-14.

8. Švec J., Sundberg J., Hertegård S. (2008). Three registers in an untrained female singer analyzed by videokymography, strobolaryngoscopy and sound spectrography. J. Acoust. Soc. Am. 123(1): 347-353.

9. Garnier M., Henrich N., Smith J., Wolfe J. (2010). Vocal tract adjustments in the high soprano range. J. Acoust. Soc. Am. 127(6): 3771-3780.

10. Roubeau B., Henrich N., Castellengo M. (2009). Laryngeal vibratory mechanisms: the notion of vocal register revisited, J. Voice 23(4): 425438

11. Schultz P. (1902). Über einen fall von willkürlichem laryngealen pfeifen beim menschen, Arch.f. Physiol. Suppl. 523.

12. Lullies H. (1953). Physiologie der stimme und sprache. In: Gehör - Stimme - Sprache (eds. Ranke O. F. and Lullies H.) Springer-Verlag: Berlin, pp. 163293.

13. McKinney J. (1994). The Diagnosis and Correction of Vocal Faults. Genovex Music Group, ISBN 978-1-56593-9400 .

14. Miller D.G. (2000). Registers in singing: empirical and systematic studies in the theory of the singing voice. Groningen: University of Groningen.

15. Wise T. (2007). Yodel Species: A Typology of Falsetto Effects in Popular Music Vocal Styles. Radical Musicology 2: 57 pars. 
16. Giles P. (2005). A Basic Countertenor Method. Kahn \& Averill Publishers: London.

17. Quinton R. (2012) Idiopathic hypogonadotrophic, hypogonadism and abnormalities of the GnRH pulse generator. Endocrinology 22: 15-20.

18. Brett B. (2004). Uproar's Your Only Music. Exile Editions: Toronto.

19. MacColl G., Bouloux P., Quinton R. (2002). Kallmann syndrome: adhesion, afferents, and anosmia. Neuron 34(5): 675-8.

20. Kallmann F.J., Schönfeld W.A., Barrera S.E. (1943). The genetic aspects of primary eunuchoidism. Am J Ment Defic 48: 203-236.

21. Deeb A., Robertson A., MacColl G., Bouloux P.M.G., Gibson M., Winyard P.J.D., Woolf A.S., Moghal N.E., Cheetham T.D. (2001). Multicystic dysplastic kidney and Kallmann's syndrome: a new association? Nephrol. Dial. Transplant. 16(6): 1170-1175.

22. Boldrey R. (1994). Guide to Operatic Roles and Arias. Caldwell Publishing Company, ISBN 978-1-877761-64-5.

23. Terziani E. Hostias et Preces, Moreschi A. (1904). Gramophone \& Typewriter Company, LTD.: London.

24. Terziani E. (1889). Hostias Et Preces. Ricordi: Milan.

25. Jenkins J.S. (1998). The voice of the castrato. Lancet 351: 1877-80.

26. Edgerton M. (2005). The 21st Century Voice. Scarecrow Press: Lanham, MD.

27. Neubauer J., Edgerton M., Herzel H. (2004). Nonlinear phenomena in contemporary vocal music. J. Voice 18: $1-12$.

28. Miller, R. (2000). Training soprano voices. Oxford University Press: New York).
29. Sonninen A., Hurme P., Laukkanen A.M. (1999). The external frame function in the control of pitch, register, and singing mode: radiographic observations of a female singer. $J$. Voice 13: 319-340.

30. Echternach M., Sundberg J., Arndt S., Markl M., Schumacher M., Richter B. (2010). Vocal tract in female registers - a dynamic real-time MRI study. J. Voice 24: 133-139.

31. Van den Berg J. (1963). Vocal ligaments versus registers. NATS Bulletin 20: 16-31.

32. Van Deinse J. B. (1981). Registers. Folia Phoniat. 33: 37-50.

33. Shipp T., Lindestad P.A., MacCurtain F., Walker J.S., Welch G.E. (1988). Whistle register and falsetto voice. $J$. Voice 2: 164-167.

34. Keilmann A., Michek F. (1993). Physiologie und akustische Analysen der Pfeifstimme der Frau. Folia Phoniatr. Logop. 45: 247-255.

35. Thurman L., Welch G., Theimer A., Klitzke C. (2004). Addressing vocal register discrepancies: an alternative, science-based theory of register phenomena. In: Second International Conference on Physiology and Acoustics of Singing, Denver, Colorado, USA.

36. Rossini G. Il barbiere di Siviglia (1816). Milan: G. Ricordi, 1920 (reprinted Mineola: Dover Publications, 1989).

37. Rossini G. Una voce poco fa (Il barbiere di Siviglia), Sack E. (1936). Polydor, Mechan Copt 1936 35087-B.

38. Blonk J. (1998). Vocalor. Staalplaat STCD 112.

39. Homler A. (1989). Signals. Five Voices: Direct Sound (Greetje Bijma, Shelley Hirsch, Anna Homler, David Moss, and Carles Santos). Intakt: CD 015 . 
40. Edgerton M. Anaphora (\#62: 2001), Almut Kuehne (2010). Live recording, IC[CM] 2010 University of A Coruña: A Coruña, Spain.

41. Neubauer J. (2001). Studio recording, Technische Universitaet, Berlin.

42. Stebbins A. (2011). Private recording, Berlin.

43. Stratos D. (1978). Passagi. Cantare la voce. Altavilla Vicentina: Cramps Records, 520.6119 - VI.

44. Edgerton M. Anaphora (\#62: 2001), Rebekka Uhlig (2001). Live recording, Reservoir V Kleiner Wasserspeicher: Berlin.

45. Edgerton M. Anaphora (\#62: 2001), Angela Wingerath (2007). Studio recording, University of Abertay: Dundee, Scotland.

46. Wingerath A. (2011). Private recording, Berlin.

47. Lopez A. (2005). Live recording at Seven Network Studios. Sydney: New South Wales, Australia).

48. Sachs K. (1962). The Wellsprings of Music. The Hague: Martinus Nijhoff.

49. Levin T., Edgerton M. (1999). The throat singers of tuva. Scientific American September: 80-87.

50. Edgerton M. (1999). Multiple Sound Sources of the Vocal Tract. National Center for Voice and Speech, Status and Progress Report 13: 131-140. 